\title{
Antipruritic armamentarium with short term nutritional support solution involving silymarin and curcumin for atopic dermatitis in dogs
}

Kerem Ural ${ }^{1}$, Mehmet Gültekin ${ }^{1}$, Songül Erdoğan ${ }^{1}$, Hasan Erdoğan ${ }^{1}$

${ }^{1}$ Department of Internal Medicine, Faculty of Veterinary Medicine, Adnan Menderes University, Aydin/TURKEY

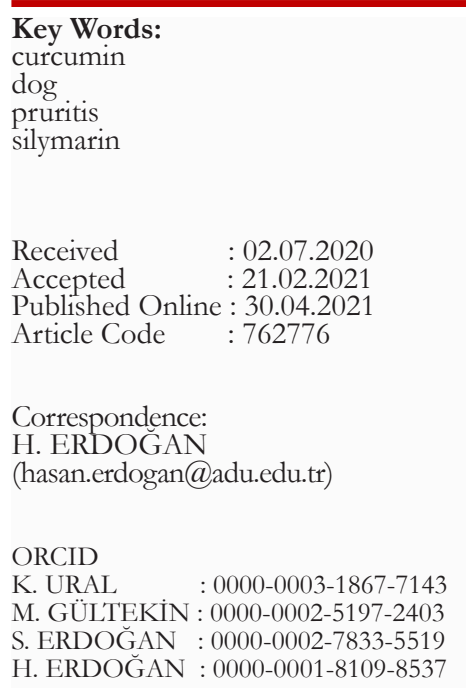

\section{INTRODUCTION}

Silymarin, a herbal derived flavonoid, obtanied from seeds and fruits from milk thistle (Silybum marianum L. Gaertn.), has been involved with the Asteraceae family Asteraceae (1). The latter mik thistle extract of milk thistle traditionaly used for therapeutic armamentarium for several disorders (2), which is now under consideration for treatment of several dermatological disorders (3).

Curcumin involved as diferuloylmethane, has long been spice, turmeric. Turmeric has gained medicinal properties (4-6). In the present study both herbal treasures were used and it was hypothesized that commercially available oral/ topical nutritional support solution involving Curcuma Longa and Silybium marianum; Silifort paste (Silp), (Aurora, Italy, Turkish side distributor Pharmax, Turkey) combination will significantly decrease the pruritus scores after short term (1 week of twice-daily) topical treatment in dogs with atopic dermatitis (Ad).

\section{MATERIAL and METHODS}

\section{Demographics}

All necessary data of was shown on table 1 . with detailed demographic values. A total of 26 dogs were included to the study (Table 1).

\section{Interpretation of analytic methods}

Diagnosis was based on necessary testing, laboratory evaluation and deemed necessary applications shown at Table 2. To those of slowly 26 cases were deemed eligible without pyoderma, mycotic secondary infection, demodicosis/scabies or endocrine disorders. This study was approved by HADYEK with number of 2019/022.

\section{Topical usage of Silp nutritional support}

Commercially available nutritional support solution invoving C. longa and S. marianum (Silifort pasta $30 \mathrm{gr}$, Aurora biofarma, Italy, Turkish side distributor Pharmax, Turkey); Silp was applied onto the lesional area(s) for a short term (1 week of twice-daily) topical treatment in dogs with Ad enrolled in this study. Control group dogs received setirizin (Zrytec oral drop) with $1 \mathrm{mg} / \mathrm{kg}$ dosage daily for a week.

\section{CADESI-04 scores}

Based on Hill's atopy index application by use of a iphone 8 plus device was recorded and obtained sum of data sent to e mail as a pdf file (automatically delivered by the application).

\section{Statistical analysis}

Treatment efficacy of the turmeric/Silymarin compared to placebo control dogs in the present study was assessed by the mean owner VAS pruritus via mean veterinarian VAS 
Table 1. Baseline characteristics of enrolled dogs

\begin{tabular}{lcc}
\hline Variable & Control group & Treatment group \\
\hline & Breed distribution [n(\%)] & \\
\hline Mixed breed & $6(60)$ & $7(56.2)$ \\
Purebred & $4(40)$ & $7(43.8)$ \\
Sex distribution [n(\%)] & $5(50)$ & $7(43.8)$ \\
$\quad$ Male & $5(50)$ & $9(56.2)$ \\
$\quad$ Female & $6.7(2-13)$ & $16.7(4-42)$ \\
$\begin{array}{l}\text { Mean age [years (range)] } \\
\text { Mean weight at study onset [kg } \\
\text { (range)] }\end{array}$ & $17.3(4-34)$ & 6.93 \\
$\begin{array}{l}\text { Owner Pruritus VAS score at } \\
\text { study onset [arithmetic mean } \\
\text { (cm)] }\end{array}$ & 6.90 & \\
$\begin{array}{l}\text { Veterinarian Dermatitis VAS } \\
\text { score at study onset [arithmetic } \\
\text { mean (cm)] }\end{array}$ & 6.70 & 6.75 \\
\hline
\end{tabular}

Table 2. Diagnosis criteria of atopic dogs.

\begin{tabular}{|c|c|c|c|}
\hline $\begin{array}{l}\text { Observational } \\
\text { criteria/parameter }\end{array}$ & Prelaud criteria & Favrot criteria & $\begin{array}{l}\text { Hill's atopy } \\
\text { index handphone } \\
\text { application }\end{array}$ \\
\hline Pruritus evaluation & $\begin{array}{l}\text { Owner Pruritus VAS } \\
\text { score at study onset } \\
\text { [mean ] }\end{array}$ & $\begin{array}{l}\text { Veterinarian Dermatitis } \\
\text { VAS score at study onset } \\
\text { [mean] }\end{array}$ & Clinical exam \\
\hline \multirow[t]{2}{*}{ Testing } & $\begin{array}{l}\text { Polycheck in vitro } \\
\text { allergen determination }\end{array}$ & Non-invasive monitoring & $\begin{array}{l}\text { Dermatological } \\
\text { examination }\end{array}$ \\
\hline & $\begin{array}{l}\text { Acetate tape } \\
\text { impression, deep skin } \\
\text { scraping, Dermlite D4 } \\
\text { dermatoscopic exam }\end{array}$ & $\begin{array}{l}\text { Excluding other } \\
\text { relevant disorders (i.e. } \\
\text { microbiological,mycological } \\
\text { lab work, endocrine } \\
\text { profile: i.e. total T4, plasma } \\
\text { cortisol values within } \\
\text { reference ranges) }\end{array}$ & \\
\hline
\end{tabular}



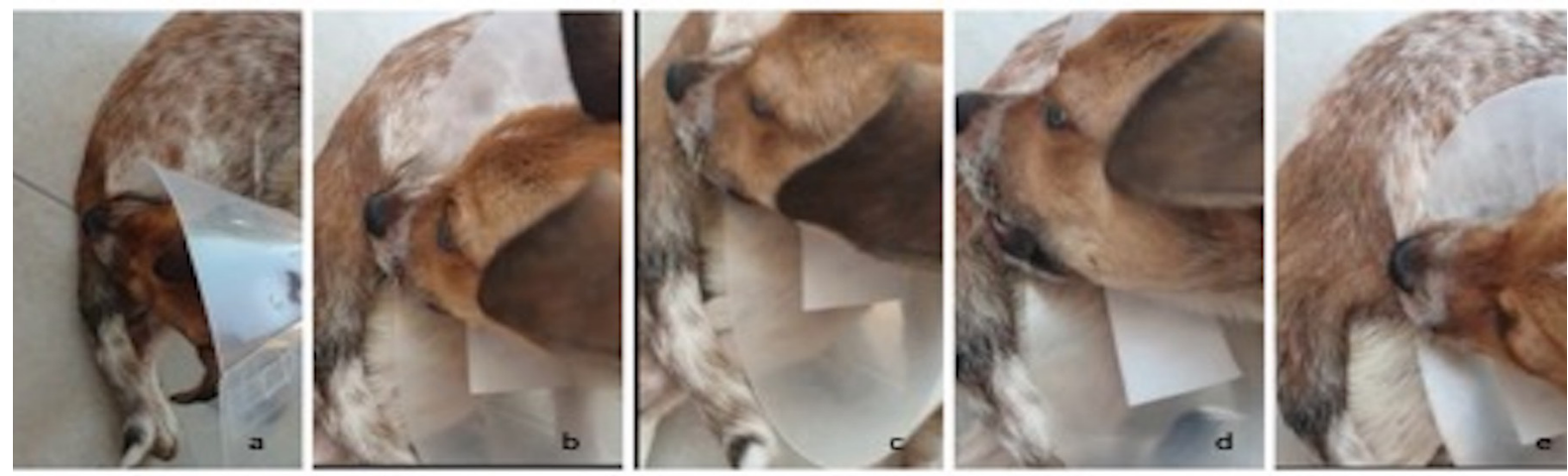

Figure 1. Slight view of pruritus behavior with in few seconds $(a-e)$. Specifically dedicated to the gut microbiome which can modulate 'gut-skin axis', tryptophan existed out via gut microbiome could participate for the pruritus, as was the case herein showed. Several seconds thereafter showed itching sensetation, licking, chewing beahviour with a pruritus score of 9. After Silp treatment of 1 week, score declined to 1 .
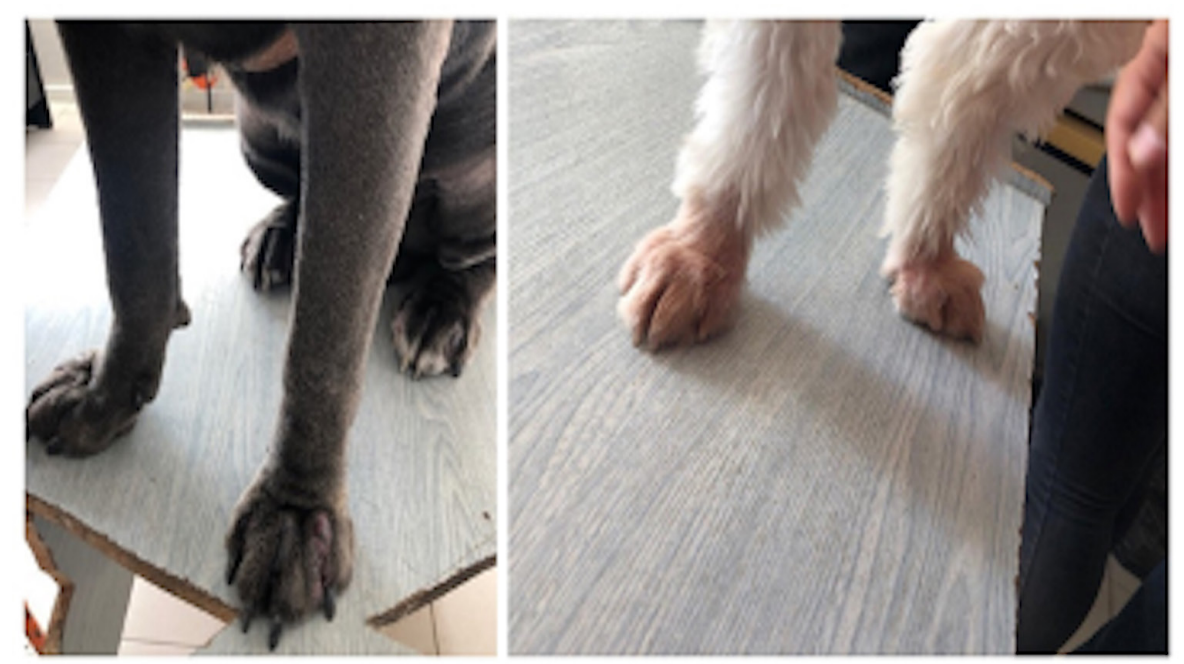

Figure 2. Two different cases diagnosed with Ad, with pododermatitis and pruritus scores of 6 and 7, respectively. After Silp treatment scores were evident as 0 and 1, respecticelyscore declined to 1.

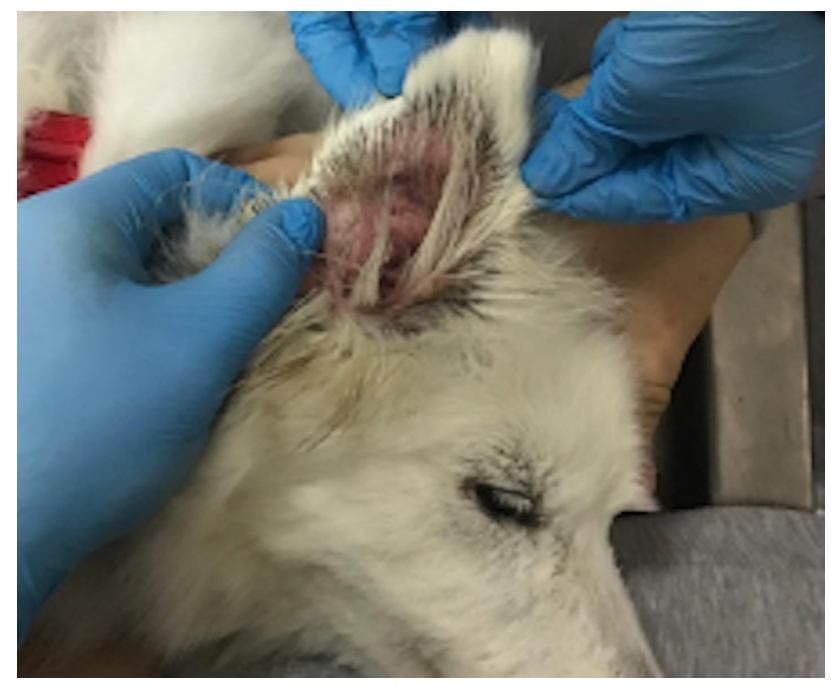

Figure 3. End stage inflammation resulting in otitis externa due to allergic reaction and histamin intolerance in Ad. This case was presented with a pruritus score of 7 , which gradually decreased to 1, after Silp treatment. 

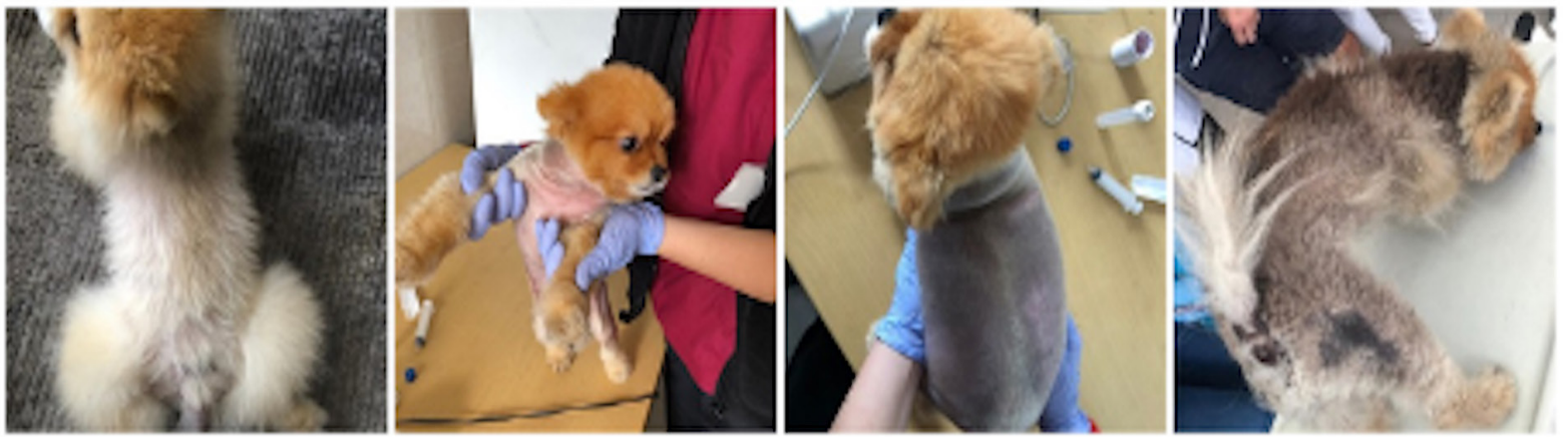

Figure 4. Ad has been extensively determined in our clinical practice within the small breeds; as the pruritus scores were $6,4,5$ and 7 , respectively with notably observed itching sensetation..

dermatitis scores on daily basis for seven days and on day 0 and 7, respectively. Repeated measures ANOVA test were used to determine the time, group and group \& time interactions. Friedman's two way-analysis of variance test were used to control the time interaction (days) for each group. To analyze the differences on each day between groups Mann-Whitney-U test were used and values $<0.05$ was recognized significant. All tests were done with package software (SPSS 22.0, SPSS Inc., USA)

\section{RESULTS}

Macroscopical view of selected cases

Owner VAS pruritus scores on each day of study

Mean 0. day owner VAS pruritus scores were similar $(\mathrm{p}>0.05)$ within the treatment groups $(6.90$ and $6.93 \mathrm{~cm}$ for the turmeric/silymarin treated dogs (range 2-10) and placebo control dogs (range 2-10), respectively. After 1 day of treatment, a $0.55 \mathrm{~cm}$ decrease of the mean owner VAS pruritus scores was observed in the treatment group, while the control dogs had a $0.27 \mathrm{~cm}$ reduction. The mean owner VAS pruritus scores continued to gradually reduction over the outstanding 6 days $(p<0.0001)$ of study in the treatment group. The mean owner VAS pruritus scores in the turmeric/silymarin treated dogs were notably lower compared to placebo treated animals on days 3 ( $p<0.01), 4(\mathrm{p}<0.001), 5,6$ and 7 ( $p<$ $0.0001)$. At day 7 , the mean owner VAS pruritus score had reduced for the turmeric/black cumin treated dogs to 0.93 $\mathrm{cm}$ (a $6 \mathrm{~cm}$ reduction, which corresponds to a decrease from "severe itching" to "normal". The reduction in the owner VAS pruritus scores for placebo treated animals after 7 days was only $1.81 \mathrm{~cm}$.

\section{Veterinarian VAS dermatitis scores on each day of study}

The mean day 0 veterinarian VAS dermatitis scores were similar ( $p>0.05)$ among the treatment groups (6.70 and 6.75 $\mathrm{cm}$ for turmeric/silymarin treated animals (range 2-10) and placebo control animals (range 2-10), separately. At day 7, mean veterinarian VAS dermatitis score for turmeric/black cumin treated animals declined to $1 \mathrm{~cm}(5.75 \mathrm{~cm}$ decrease from "moderately severe dermatitis" towards "normal"), the control animals to $5.2 \mathrm{~cm}(1.5 \mathrm{~cm}$ decrease from "moderately severe dermatitis" to "mildly moderate dermatitis") $(\mathrm{p}<0.0001)$. Veterinarian VAS dermatitis scores in the turmeric/silymarin treated animals were notably reduce compared to control dogs on day $7(\mathrm{p}<0.0001)$.

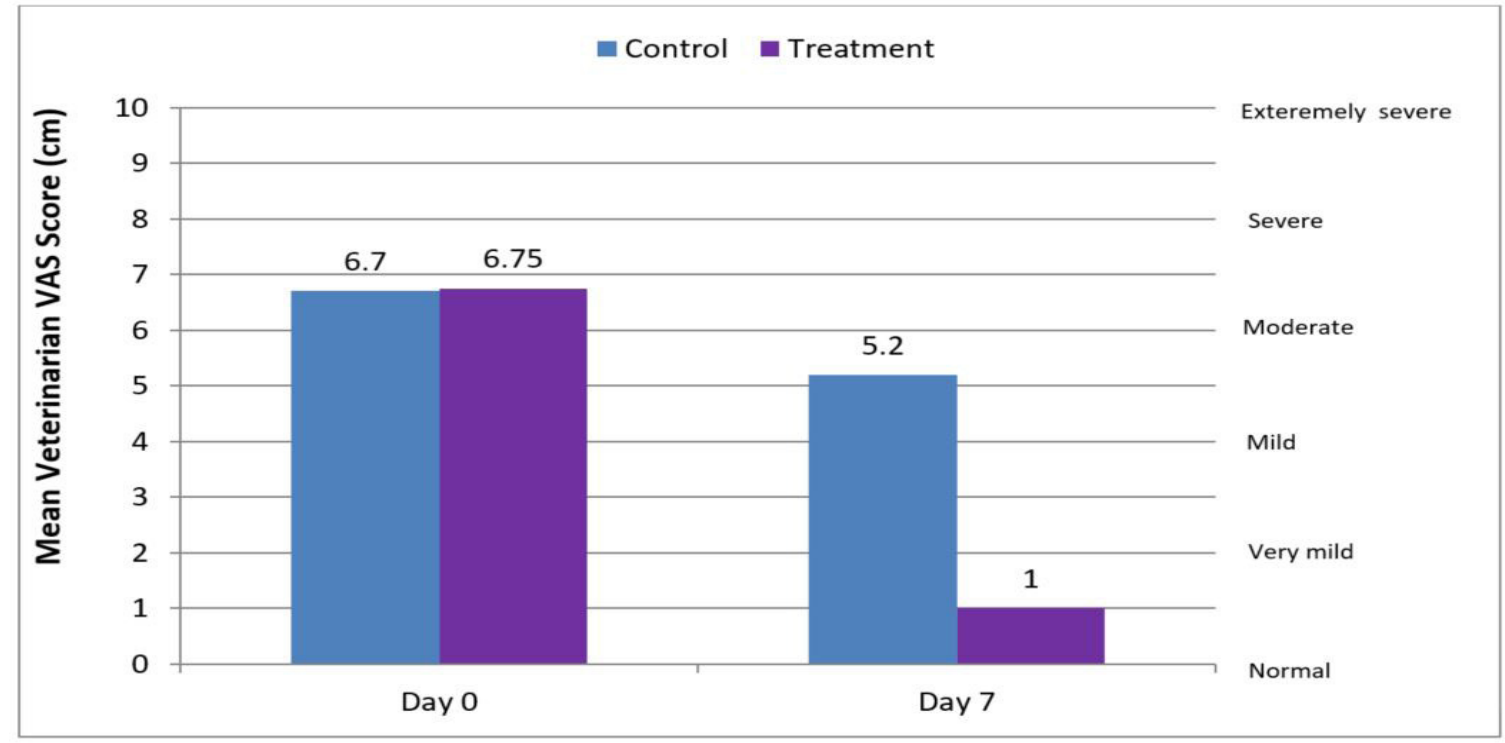

Figure 5. Mean veterinarian VAS scores throughout the study period. 


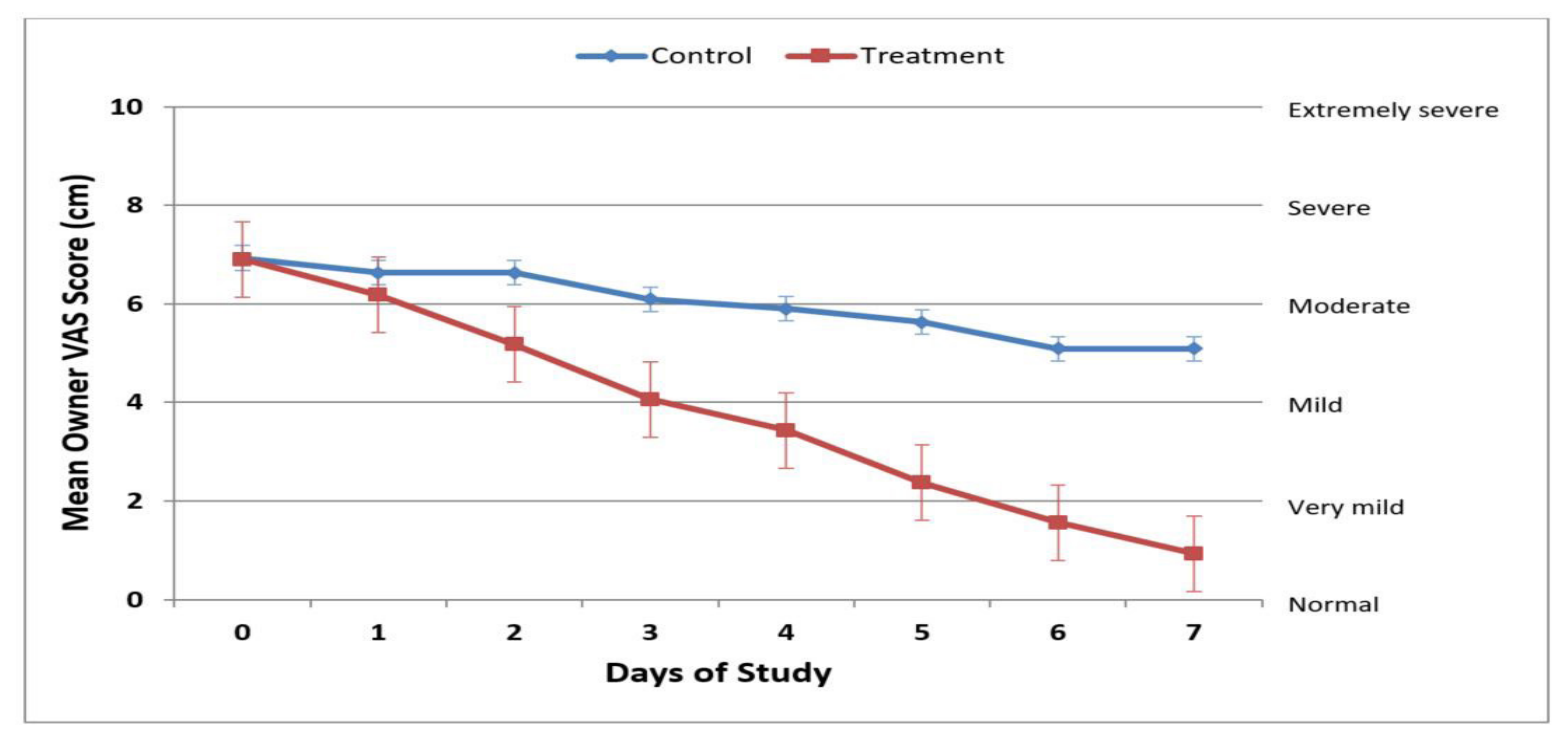

Figure 6. Mean owner VAS scores throughout the study period.

\section{CADESI-04 analytes}

Based on Hill's atopy index application by use of a iphone 8 plus device scores ranged from 11 (mild Ad) to 126 (severe Ad), which were switched to 10- 99 after Silp treatment.

\section{DISCUSSION}

The results of the present study might be comperable to a prior research investigating the efficacy of oclacitinib (ocl) against pruritus to those of dogs with allergic dermatitis. In that study after 1 week of ocl treatment, a 65\% decrement among pruritus scores (changed from 'severe to very mild itching'). Within the first day of ocl therapy, pruritus scores declined by at least $2 \mathrm{~cm}(44 \%)$ compared to those of the control-treated animals $(19 \%)$. On week 1, the vast majority of the ocl-treated dogs $(86.4 \%)$ presented a $2 \mathrm{~cm}$ decline in Owner Pruritus VAS scores when compared to placebo-treated dogs $(<42.5 \%)$. Furthermore, on week 1, 70.5\% of ocl-treated animals represented a $>50 \%$ decline in Owner Pruritus VAS scores in contrast to $<23.2 \%$ of the placebo cases. In the latter study ocl therapy resulted in treatment success $(66.5 \%$ in ocl-treated vs. $29.4 \%$ of the placebo), making ocl improving pruritus and dermatitis (7). In comparison in the present study mean 0 . day owner VAS pruritus scores were similar $(p>0.05)$ between the treatment groups $(6.90$ and $6.93 \mathrm{~cm}$ for the Silp treated dogs (range 2-10) and control dogs (range 2-10), respectively. After 1 day of Silp treatment, a $0.55 \mathrm{~cm}$ decrement of mean owner VAS pruritus scores was detected in treatment group, while the control dogs had a $0.27 \mathrm{~cm}$ reduction. The mean owner VAS pruritus scores persistent to gradually reduce over other 6 days of study in the treatment group $(\mathrm{p}<0.0001)$. The mean owner VAS pruritus scores in the Silp treated dogs were notably lower compared to control treated dogs on days $3(\mathrm{P}<0.01)$, $4(\mathrm{p}<0.001), 5,6$ and $7(\mathrm{p}<0.0001)$. At day 7, the mean owner VAS pruritus score had reduced for the Silp treated animals to $0.93 \mathrm{~cm}$ (a $6 \mathrm{~cm}$ decrement, which means a decrease from "severe itching" to "normal". The decrease in owner VAS pruritus scores for control treated animals after 7 days was only $1.81 \mathrm{~cm}$.
Instant depression (probably) of the activity of pruritogenic cytokines [i.e. Interleukin-31], might briefly define the quick decline in pruritus thereafter ocl therapy (8). Hence by management of the pruritus in dogs, a direct anti-inflammatory action might also occur within the dermis. Similarly in the present study a better understanding for the Silp treatment option could be available with the expression of the compound ingredients. Turmeric has a well-known interaction with several molecular targets participating within inflammation (9). The latter spice, reduce the amplitude of the inflammatory respond by down-regulating the activities of cyclooxygenase-2, lipoxygenase and nitric oxide synthase (9). Anti-inflammatory effects of curcumin might be dedicated to downregulation of the expression of TNF- $\alpha$, cyclin D and cell surface adhesion molecules (10). In addition inhibition the activity of protein serine/threonine kinases, c-Jun N-terminal kinase and protein tyrosine kinase, might participate (11). From another point of view curcumin selectively inhibits phosphorylase kinase (12), the enzyme participate for breaking down glycogen, for formation of ATP, with a significant role for phosphorylation (13). The latter enzyme may be released only 300 seconds after injury, activating inflammatory cells (13-15), wound healing and scar tissue formation (16). Given the efficacy of curcumin able to inhibit phosphorylase kinase activity might have the potential for modulation of the inflammatory respond for influencing above mentioned factors. In the present study the oral compund used involved curcumin, in which supported the decreased VAS scales and related scoring by probable antiinflammatoric action as reported previously and explorated from human studies (8-16).

In the present study interpretation of pruritus was based on VAS scales, as was also reported and determined previoulsy (7). In that research enhanced VAS scales were presented as an easy and quotable technique for practioners for assessing the severity of pruritus $(20,22)$. In previous researches, a VAS scale was preferred for assessment of itching (23). Indeed, dogs may not truly present itching behaviour on referral. Thus scientists or practioners pruritus VAS score might have to lean on what the patient's owner report rather than observation 
(7). On the other hand regarding Canine Atopic Dermatitis and Severity Index (CADESI), has long been known as an objective and validated assessment tools with limited usage confined now to atopic dermatitis, and might not be suitable for assessing the degree of the skin disorders (7), observed in this study. Enhanced dermatitis VAS used and adopted previously (7), which also adopted in the present study might have been useful for free veterinary surgeons participating at special practice with no special education nor certification in veterinary dermatology (7).

Berardesca et al. (17) denoted that silymarin alog with methylsulfonylmethane were found effective for relieving pruritus and relevant clinical signs at erythemato-telangiectatic phase of rosacea subtype-1. On the other hand topical silymarin diminished atopic dermatitis by suppression of mast cell infiltration in mice skin (18). Hence silymarin was able to reduce plasma IL-4 and IgE levels to those of mice. It has been postulated that silymarin be helpful for atopic dermatitis treatment (18). Mady et al.(19) used specifical silymarin formulation significantly diminshed redness, swelling, and inflammation in atopic dermatitis. Al those afromentioned mechanisms might be possibly interact with the anti-pruritic armamentarium obtained in this study.

\section{CONCLUSION}

In conclusion it may be suggested that, curcumin, a selective Janus kinase inhibitor, prescribed per twice daily, along with silymarin, were both safe and effective for releiving pruritus in association with allergy in dogs. This natural (herbal in origin) compounds offered itch relief within 24 hours as was observed throughout study period, with the vast majority of treated animals presented a $5.75 \mathrm{~cm}$ decrease on pruritus (from "moderately severe dermatitis" to "normal") by day 7 . It should not be unwise to draw conclusion that this herbal compound might have helped pruritus relief and might be used with safety as an antipruritic agent.

\section{DECLARATIONS}

\section{Ethics Approval}

This study was approved by animal ethics committee of the Aydin Adnan Menderes University (No: 2019/022), Aydın.

\section{Conflict of Interest}

The authors declare that they have no competing interests.

\section{Author Contribution}

Idea, concept and design: K Ural

Data collection and analysis: K Ural, M Gültekin, S Erdoğan, H Erdoğan

Drafting of the manuscript: K Ural, M Gültekin, S Erdoğan, H Erdoğan

Critical review: K Ural, M Gültekin, S Erdoğan, H Erdoğan

\section{Data Availability}

The data that support the findings of this study are available from the corresponding author upon reasonable request.

\section{REFERENCES}

1. Wagner H, Diesel P, Seitz M. The chemistry and analysis of silymarin from Silybum marianum Gaertn. ArzneimittelForschung. 1974;24(4):466-471.

2. Schuppan D, Jia JD, Brinkhaus B, Hahn EG. Herbal products for liver diseases: A therapeutic challenge for the new millennium. Hepatology. 1999;30:1099-104.

3. Dorjay K, Arif T, Adil M. Silymarin: An interesting modality in dermatological therapeutics. Indian J Dermatol Venereol Leprol. 2018;84(2):238

4. Sharma RA, McLelland HR, Hill KA, Ireson CR. Euden SA, Manson MM, Steward WP. Pharmacodynamic and pharmacokinetic study of oral Curcuma extract in patients with colorectal cancer. Clin Cancer Res. 2001;7:1894-1900.

5. Garcea G, Berry DP, Jones DJL, Singh R, Dennison AR, Farmer PB, Gescher AJ. Consumption of the putative chemopreventative agent curcumin by cancer patients: Assessment of curcumin levels in the colorectum and their pharmacodynamics consequences. Cancer Epidemiol Biomarkers Prev. 2005;14:120-125.

6. Siviero A, Gallo E, Maggini V, Gori L, Mugelli A, Firenzuoli F, Vannacci A. Curcumin, a golden spice with low bioavailability. J Herbal Med 2015;5:57-70.

7. Cosgrove SB, Wren JA, Cleaver DM, Martin DD, Walsh KF, Harfst JA, Stegemann MR. Efficacy and safety of oclacitinib for the control of pruritus and associated skin lesions in dogs with canine allergic dermatitis. Vet Dermatol. 2013;24(5):479-e114.

8. Gonzales AJ, Humphrey WR, Messamore JE, Fleck TJ, Fici GJ, Shelly JA, et al.. Interleukin $\square$ 31: its role in canine pruritus and naturally occurring canine atopic dermatitis. Vet Dermatol. 2013;24(1):48-e12.

9. Lantz RC, Chen GJ, Solyom AM, Jolad SD, Timmermann $\mathrm{BN}$. The effect of turmeric extracts on inflammatory mediator production. Phytomedicine. 2005;12(6-7):445-452.

10. Sandur SK, Ichikawa H, Pandey MK, Kunnumakkara AB, Sung B, Sethi G, et al. Role of pro-oxidants and antioxidants in the anti-inflammatory and apoptotic effects of curcumin (diferuloylmethane). Free Radic Biol Med. 2007;43(4):568-580.

11. Aggarwal B, Kumar A, Bharti AC. Anticancer potential of curcumin: preclinical and clinical studies. Anticancer Res. 2003;23:363-398.

12. Reddy S, Aggarwal BB. Curcumin is a non-competitive and selective inhibitor of phosphorylase kinase. FEBS Lett. 1994;341:19-22.

13. Heng MC, Song MK, Heng MK. Elevated phosphorylase kinase activity in psoriatic epidermis: correlation with increased phosphorylation and psoriatic activity. Br J Dermatol. 1994;130:298-306.

14. Heng MC, Song MK, Harker J, Heng MK. Drug-induced 
suppression of phosphorylase kinase activity correlates with resolution of psoriasis as assessed by clinical, histological and immunohistochemical parameters. $\mathrm{Br} \mathrm{J}$ Dermatol. 2000;143:937-949.

15. Heng MC. Signaling pathways targeted by curcumin in acute and chronic injury: burns and photodamaged skin. Int J Dermatol. 2013;52:531-543.

16. Heng MC. Wound healing in adult skin: aiming for perfect regeneration. Int J Dermatol. 2011;50:1058-1066.

17. Berardesca E, Cameli N, Cavallotti C, Levy JL, Piérard GE, de Paoli Ambrosi G. Combined effects of silymarin and methylsulfonylmethane in the management of rosacea: Clinical and instrumental evaluation. J Cosmet Dermatol. 2008;7:8-14.

18. Kang JS, Yoon WK, Han MH, Lee H, Lee CW, Lee $\mathrm{KH}$, et al. Inhibition of atopic dermatitis by topical application of silymarin in $\mathrm{NC} / \mathrm{Nga}$ mice. Int Immunopharmacol. 2008;8:1475-80.

19. Mady FM, Essa H, El-Ammawi T, Abdelkader H, Hussein AK. Formulation and clinical evaluation of silymarin pluronic-lecithin organogels for treatment of atopic dermatitis. Drug Des Devel Ther. 2016;10:1101-10. 